\title{
Determination of the Maximal Lactate Steady State by HRV in Overweight and Obese Subjects
}

\section{(๑)( $\odot \Theta$}

\author{
Authors \\ Tobias Schmidt1,2, Sarah Wulff², Klaus-Michael Braumann², Ruediger Reer²
}

\section{Affiliation}

1 Institute of General Practice, University Medical Center Göttingen

2 Department of Sports and Exercise Medicine, Institute of Human Movement Science, University of Hamburg, Hamburg, Germany

\section{Key words}

exercise testing, HRV, MLSS, obese, overweight, performance

$\begin{array}{ll}\text { received } & 12.07 .2018 \\ \text { revised } & 15.02 .2019 \\ \text { accepted } & 16.03 .2019\end{array}$

Bibliography

DOI https://doi.org/10.1055/a-0883-5473

Sports Medicine International Open 2019; 3: E58-E64

(C) Georg Thieme Verlag KG Stuttgart · New York

ISSN 2367-1890

\section{Correspondence}

Dr. Tobias Schmidt

Institute of General Practice,

University Medical Center Göttingen,

Humboldtallee 38,

37073 Göttingen,

Germany

Tel.: + 49/551/3965745, Fax: + 551/399530

tobias.schmidt@med.uni-goettingen.de

\begin{abstract}
The study assessed if the maximal lactate steady state (MLSS) may be determined by HRV in overweight and obese individuals. Fourteen obese $(\mathrm{OB})$ and 14 overweight $(\mathrm{OW})$ participants performed an incremental exercise test and several constantload tests on a bicycle ergometer to determine the MLSS. HRV was analysed by using time domain and non-linear parameters of the Poincaré plot. Various HRV thresholds (HRVt) were detected and compared with the MLSS. Overall, Bland-Altman plots demonstrated moderate to strong agreements between the power at the MLSS and the power at HRVt, with all HRVt overestimating the MLSS (range: -14.6 to $-19.8 \mathrm{~W}$ ). All HRVt were detected at higher intensities $\left(69.2-78.8 \% \mathrm{P}_{\max }\right)$ compared to the MLSS $\left(62.6-66.8 \% \mathrm{P}_{\max }\right)$. The primarily vagally modulated parameter $\mathrm{HRVt}_{\mathrm{SD} 1}$ revealed higher correlations $(r=0.66-0.76)$ and lower differences $(16.8-19.9 \%)$ compared to the parameter $\mathrm{HRVt}_{\mathrm{SD} 2}(r=0.56-r=0.66 ; 22.4-22.9 \%)$. The data suggest a delayed vagal withdrawal during incremental exercise in obese and overweight individuals. For this population, the use of HRV to determine the MLSS seems questionable.
\end{abstract}

\section{Introduction}

Obesity is still a major health problem with an increased incidence [23]. It is associated with other cardiovascular risk factors and increased risk of all-cause mortality [39]. In the treatment of obesity, physical exercise is an intensely investigated and essential part. Various reviews state beneficial effects of traditional moderate-intensity continuous training (MICT) and short-term high-intensive training (HIT) on cardiovascular risk factors in obesity [19,29]. The success of these training programs is based on the optimal exercise intensity. In this context, there are various commonly used methods of estimating exercise intensities: oxygen uptake reserve $\left(\mathrm{VO}_{2 \mathrm{R}}\right)$, heart rate reserve $(\mathrm{HRR})$, per- cent of the maximum heart rate $\left(\% \mathrm{HR}_{\max }\right)$ and percent of the maximal oxygen uptake $\left(\% \mathrm{VO}_{2 \max }\right)$ [14]. All of these methods depend on the adequate motivation of the investigated subject, which seems problematic especially for untrained and overweight persons.

In light of this, research focuses on the detection of the anaerobic threshold (ANT) and is intensely investigated. The ANT may typically be determined through use of graded exercise tests by analysis of blood lactate concentration [12]. When defining the areas of training and determining individual intensity ranges, the application of graded exercise tests and analysis of blood lactate concentration is to be preferred to the $\mathrm{HF}_{\max }$ and $\mathrm{VO}_{2 \max }$ Procedures 
$[12,32]$. The gold standard method to detect the ANT is the determination of the maximal lactate steady state (MLSS) [12]. The MLSS is defined as the highest constant workload that still leads to an equilibrium between lactate production and lactate elimination $[6,12]$. The determination of the MLSS requires several submaximal exercise tests and the analysis of blood lactate concentration on different days [6]. However, this approach entails the use of an invasive method that requires high organizational effort and time.

In the last 3 decades, heart rate variability (HRV) has frequently been investigated during physical activity [2] in relation to training adaptations [26] and for monitoring athletic training status [5]. In this context, various studies investigated the relationship between ANT and HRV. Several investigations demonstrated high agreements between different lactate thresholds (LT) with so-called HRV thresholds (HRVt): Karapetian et al. [18] demonstrated high correlations of LT and HRVt in 28 subjects with a wide range of aerobic capacities and fitness levels on a bicycle ergometer. Di Michele et al. [21] compared LT and HRV in 14 high-level swimmers and reported high agreements of HRVt and LT. To our knowledge, only one study group so far has focused on the relationship between HRV and the MLSS: Flöter et al. [13] demonstrated a high agreement between HRVt and the MLSS in well-trained athletes.

However, several cross-sectional studies reported a reduction of HRV in overweight and obese individuals compared to normalweight persons $[22,28,40]$. It is assumed that the reduction of HRV is mainly caused by depression of cardiac parasympathetic activity $[22,25]$. Recent evidence furthermore suggests that cardiac autonomic regulation may play an important role in exercise tolerance [4]. Therefore, it can be assumed that body fat influences parasympathetic regulation and, as a consequence, affects physical performance. To the best of our knowledge, there are no studies that compared HRV and the MLSS in overweight and obese subjects. Consequently, the aim of this study was to assess if the MLSS may be detected by HRV in overweight and obese individuals. The hypothesis of this study was that the MLSS could be detected by HRV in overweight and obese individuals.

\section{Methods}

\section{Participants}

Participants were recruited within the Hamburg area in Germany via word of mouth, flyers, social media, and advertisements. Participants were included in the study if they were (1) aged between 18 to 60 years; (2) BMI between 25 to $40 \mathrm{~kg} \cdot \mathrm{m}^{-2}$; and (3) abdominal girth: male $>102 \mathrm{~cm}$, female $>96 \mathrm{~cm}$. The sample size was divided into two groups: overweight participants (OW) with a BMI between 25 to $29.9 \mathrm{~kg} \cdot \mathrm{m}^{-2}$ and obese participants (OB) with a BMI between 29.9 to $40 \mathrm{~kg} \cdot \mathrm{m}^{-2}$. Participants were excluded if they suffered from systemic disorders, such as diabetes, heart disease, metabolic diseases, severe orthopedic disorders, acute or chronic infections, or mental disorders. All participants provided written informed consent. The study was conducted in accordance with the ethical standards required by the journal [16] and was approved by the Ethics Committee of the Hamburg Medical Council (PV3592).

\section{Testing procedure}

The investigation was performed at the Institute of Human Movement Science, University of Hamburg. The study protocol included 1 incremental exercise test and 2 to 3 constant submaximal load tests on a cycle ergometer within a period of 4 weeks. The bicycle ergometer was chosen due to the minimal electrocardiogram (ECG) artefacts during exercise. The incremental test was performed to measure HRV, to calculate the load for the first constant-load test, and to assess the level of $\mathrm{VO}_{2 \text { peak }}$. The constant-load tests were conducted to determine the MLSS. Before testing, participants were familiarized with the experimental procedure. Intensive physical activity and consuming alcohol and caffeine within $24 \mathrm{~h}$ were prohibited. All tests were conducted at the same time of day. Intervals between tests were at least 2 days and at most 7 days. All tests were conducted on a bicycle ergometer whose rotational speed was independent and that slowed down electromagnetically (Lode Excalibur Sport 1000 W, Lode BV Medical Technology, Groningen, Netherlands). In all tests, the participants were required to ride with a pedal rotation of $60-90$ rotations $\cdot \mathrm{min}^{-1}$. Each test started with a warm-up period of $5 \mathrm{~min}$ at $25 \mathrm{~W}$ and ended with an active recovery period of 5 min at $25 \mathrm{~W}$.

\section{Incremental exercise test}

Work load was first applied at an intensity of $25 \mathrm{~W}$ and was increased by $8.3 \mathrm{~W} \cdot \mathrm{min}^{-1}$, resulting in $25 \mathrm{~W}$ every $3 \mathrm{~min}$ up to volitional exhaustion [3]. Capillary blood samples were taken in the beginning, every $3 \mathrm{~min}$, and in the first, third and fifth post-exercise minute. During the tests, continuous electrocardiograms (ECGs) were taken to calculate the HRV.

\section{Constant-load tests}

Each constant-load test included a warm-up period and a 30-min workload exercise bout. The initial workload for the first constantload test based on the threshold determination according to Stegmann [31] measured during the incremental exercise test. In the beginning and every 3 min within the last 20 min capillary blood samples were taken. If a steady state of the blood lactate concentration (BLC) was achieved or BLC decreased during constant workload, the following constant load was increased by $3-10 \%$ of the initial value. If blood lactate concentration increased or the test could not be completed due to exhaustion, the subsequent constant workload was conducted at a reduced workload intensity [6].

\section{Blood lactate analysis}

Capillary blood samples $(25 \mu \mathrm{l})$ were taken from the earlobe and were automatically analyzed. The lactate concentration was calculated by using Ebio plus (C line, EKF-Diagnostik, Germany) [13].

\section{Gas measurements}

The exhaled gases for the determination of the $\mathrm{VO}_{2 \text { peak }}$ were measured breath by breath (Oxycon Pro; Jaeger, Bunnik, Netherlands). $\mathrm{VO}_{2 \text { peak }}$ values were calculated as the mean of the two highest 30 -s records.

\section{Anthropometry}

Height, weight, and abdominal girth were measured directly before testing. Body fat was determined with the help of a caliper [24]. 
- Table 1 Characteristics of study participants.

\begin{tabular}{|c|c|c|c|c|}
\hline Characteristic & All $(n=28)$ & Overweight subjects $(n=14)$ & Obese subjects $(n=14)$ & p-value \\
\hline Age (years) & $38.5 \pm 13.1$ & $38.9 \pm 12.7$ & $38.1 \pm 13.9$ & 0.877 \\
\hline Height $(\mathrm{cm})$ & $176.1 \pm 8.7$ & $176.6 \pm 5.8$ & $176.5 \pm 11.0$ & 0.766 \\
\hline Weight $(\mathrm{kg})$ & $96.4 \pm 16.7$ & $86.1 \pm 7.9$ & $106.6 \pm 17.0$ & $<0.000$ \\
\hline Body mass index $\left(\mathrm{kg} \cdot \mathrm{m}^{-2}\right)$ & $30.9 \pm 4.4$ & $27.4 \pm 1.6$ & $34.4 \pm 3.4$ & $<0.000$ \\
\hline Body fat (\%) & $29.2 \pm 4.3$ & $27.8 \pm 4.5$ & $30.6 \pm 3.8$ & 0.088 \\
\hline Abdominal girth $(\mathrm{cm})$ & $107.8 \pm 10.9$ & $100.1 \pm 6.7$ & $115.5 \pm 8.6$ & $<0.000$ \\
\hline Waist to hip ratio & $0.9 \pm 0.09$ & $0.86 \pm 0.1$ & $0.93 \pm 0.07$ & 0.048 \\
\hline $\mathrm{VO}_{2 \text { peak }}\left(\mathrm{ml} \cdot \mathrm{kg}^{-1} \cdot \mathrm{min}^{-1}\right)$ & $31.5 \pm 7.6$ & $34.2 \pm 8.3$ & $29.2 \pm 5.6$ & 0.106 \\
\hline Absolute maximum power (W) & $193.8 \pm 32.8$ & $199.6 \pm 30.9$ & $188.9 \pm 34.8$ & 0.439 \\
\hline Relative maximum power $\left(\mathrm{W} \cdot \mathrm{kg}^{-1}\right)$ & $2.1 \pm 0.4$ & $2.2 \pm 0.4$ & $1.9 \pm 0.3$ & 0.044 \\
\hline Absolute power at MLSS (W) & $126.6 \pm 30.7$ & $125.4 \pm 30.7$ & $127.3 \pm 30.0$ & 0.439 \\
\hline Relative power at MLSS $\left(\mathrm{W} \cdot \mathrm{kg}^{-1}\right)$ & $1.3 \pm 0.4$ & $1.5 \pm 0.4$ & $1.2 \pm 0.3$ & 0.089 \\
\hline
\end{tabular}

- Table 2 Group differences for performance characteristics.

\begin{tabular}{|c|c|c|c|}
\hline & $\begin{array}{l}\text { Mean } \\
\text { difference }\end{array}$ & {$[95 \% \mathrm{Cl}]$} & p-value \\
\hline Relative $\mathrm{VO}_{\text {2peak }}\left(\mathrm{ml} \cdot \mathrm{kg}^{-1} \cdot \mathrm{min}^{-1}\right)$ & 5.0 & {$[-1.2-11.3]$} & 0.106 \\
\hline Absolute maximum power (W) & 10.7 & {$[-13.6-38.8]$} & 0.439 \\
\hline Relative maximum power $\left(\mathrm{W} \cdot \mathrm{kg}^{-1}\right)$ & 0.3 & {$[0.0-0.63]$} & 0.044 \\
\hline Absolute power at MLSS (W) & 1.9 & $\begin{array}{l}{[-26.8-} \\
23.0]\end{array}$ & 0.877 \\
\hline Relative power at MLSS $\left(\mathrm{W} \cdot \mathrm{kg}^{-1}\right)$ & 0.3 & $\begin{array}{l}{[-0.43-} \\
0.56]\end{array}$ & 0.089 \\
\hline \multicolumn{4}{|c|}{$\begin{array}{l}\text { Data are reported as mean and } 95 \% \text { confidence interval }[\mathrm{Cl}] \text {; } \\
\text { Abbreviations: } \mathrm{MLSS}=\text { maximal lactate steady state, } \mathrm{W}=\text { watt. }\end{array}$} \\
\hline
\end{tabular}

\section{Maximal lactate steady state}

MLSS represents the highest constant workload that still leads to equilibrium between lactate production and lactate elimination [12]. More precisely, the MLSS is defined as the highest workload during which blood lactate concentration (BLC) increases by no more than $1.0 \mathrm{mmol} \cdot \mathrm{I}^{-1}$ during the final $20 \mathrm{~min}$ of a $30 \mathrm{~min}$ constant-load test $[6,17]$. The gold standard for the determination of the MLSS is performing several constant load trials of at least $30 \mathrm{~min}$ duration on different days at various exercise intensities [12].

\section{Heart rate variability analysis}

During the incremental exercise test, $R$ waves were automatically detected from a 12-channel ECG (vicardio, GETEMED, Teltow, Germany) (sample rate: $1000 \mathrm{~Hz}$ ). The raw set of data for the intervals between successive heartbeats (RR intervals) was visually monitored and cleared of artefacts before being imported into specifically developed software (vicardio). The data was filtered by a digital 5th-order Butterworth low-pass filter $(8 \mathrm{~Hz})$. Only RR intervals with a deviation of less than $75 \%$ from the preceding or following $R R$ interval were accepted. To illustrate the complete variability of the heart rate, the standard deviation of RR intervals (SDNN) was calculated. Furthermore, we conducted a quantitative analysis of the Poincaré plot and calculated the standard deviation of the transverse axis (SD1) and of the longitudinal axis (SD2) [36, 37].

\section{Heart rate variability thresholds}

Each HRV parameter was separately analyzed in the range between $50 \%$ and $80 \%$ of the maximum power in $\mathrm{W}\left(\mathrm{P}_{\max }\right)$, because the ANT is expected to be in this range $[13,18]$. The last 2 min of each exercise stage were subdivided into segments of 50 RR intervals. The moving average was calculated and displayed on a curve [13]. For the parameter SD1, the minimum value of the curve was defined as the HRVt $\left(\mathrm{HRVt}_{\mathrm{SD} 1}\right)$. For the parameter SD2 and SDNN the onset of the plateau phase [13] was defined as the HRVt (HRVt $t_{\text {SD2 }}$ and $\mathrm{HRVt}_{\mathrm{SDNN}}$ ). The corresponding power $(\mathrm{W})$ value was identified for further use in the statistical analysis.

\section{Statistical analysis}

Data are expressed as mean with standard deviation and $95 \%$ confidence interval $(\mathrm{Cl})$. The power output at the MLSS and HRVt are expressed as absolute values $(\mathrm{W})$ and in relation to maximal power $\left(\% \mathrm{P}_{\max }\right)$. Differences of power output between the MLSS and HRVt are expressed as a percentage. The Kolmogorov-Smirnov test was used to test for normal distribution. Mean differences between OW and OS were tested using the Student's t-test and Mann-Whitney test. Mean values of power output (W) at the MLSS and at each HRVt were compared by Pearson's and Spearman's correlation coefficients. Additionally, Bland-Altman plots were used to test relationships between the MLSS and HRVt [10]. Statistical significance was set at $p<0.05$. Statistical analysis was performed using SPSS $^{\odot} 21.0$.

\section{Results}

For 2 participants, HRVt could not be determined because the quality of the ECG was insufficient. One participant discontinued the trial without giving a reason and another subject was not able to perform the endurance tests to determine the MLSS. Characteristics of the remaining study participants $(n=28)$ are shown in - Table 1. Performance characteristics are listed in > Table 2. Correlation coefficients between power output at the MLSS and power output at the HRVt parameters are shown in > Table 3. There were no significant differences for mean power output at any HRVt parameter and the MLSS between groups ( $>$ Table 3 ). HRVt and the MLSS could be detected between 62.6 to $77.6 \%$ of $\% \mathrm{P}_{\max }$, with no 
- Table 3 Absolute power output and correlations to MLSS of study participants.

\begin{tabular}{|c|c|c|c|c|c|c|c|}
\hline & \multicolumn{2}{|l|}{ All } & \multicolumn{2}{|c|}{ Overweight $n=13$} & \multicolumn{3}{|l|}{ Obese $n=11$} \\
\hline & Power (W) & Correlation $r^{2}$ & Power (W) & Correlation $r^{2}$ & Power (W) & Correlation $r^{2}$ & p-value \\
\hline MLSS & $126.6 \pm 30.7$ & & $125.4 \pm 30.7$ & & $127.3 \pm 30.0$ & & 0.877 \\
\hline $\mathrm{HRVt}_{\mathrm{SD} 1}$ & $144.8 \pm 31.9$ & $0.69 * *$ & $143.9 \pm 37.0$ & $0.66^{*}$ & $145.9 \pm 26.6$ & $0.76^{* *}$ & 0.879 \\
\hline $\mathrm{HRVt}_{\mathrm{SD} 2}$ & $146.1 \pm 30.1$ & $0.60^{*}$ & $146.5 \pm 31.5$ & $0.66^{*}$ & $145.5 \pm 28.4$ & 0.56 & 0.933 \\
\hline $\mathrm{HRVt}_{\text {SDNN }}$ & $142.3 \pm 31.3$ & $0.56^{*}$ & $145.4 \pm 34.4$ & $0.56^{*}$ & $138.6 \pm 28.4$ & 0.59 & 0.609 \\
\hline
\end{tabular}

- Table 4 Power output in relation to maximal power and differences of HRVt to MLSS of study participants.

\begin{tabular}{|c|c|c|c|c|c|c|}
\hline & \multicolumn{2}{|l|}{ All } & \multicolumn{2}{|l|}{ Overweight $n=13$} & \multicolumn{2}{|l|}{ Obese $n=11$} \\
\hline & $\begin{array}{l}\text { Power in relation } \\
\text { to } P_{\max }(\%)\end{array}$ & $\begin{array}{l}\text { Difference to } \\
\text { MLSS (\%) }\end{array}$ & $\begin{array}{l}\text { Power in relation } \\
\text { to } P_{\max }(\%)\end{array}$ & $\begin{array}{l}\text { Difference to } \\
\text { MLSS (\%) }\end{array}$ & $\begin{array}{l}\text { Power in relation } \\
\text { to } P_{\max }(\%)\end{array}$ & $\begin{array}{l}\text { Difference to } \\
\text { MLSS (\%) }\end{array}$ \\
\hline MLSS & $64.9 \pm 7.4$ & & $66.8 \pm 7.1$ & & $62.6 \pm 7.4$ & \\
\hline $\mathrm{HRVt}_{\mathrm{SD} 1}$ & $74.5 \pm 8.4$ & $19.9 \pm 16$ & $75.9 \pm 10.5$ & $22.4 \pm 15.6$ & $72.9 \pm 4.8$ & $16.8 \pm 16.6$ \\
\hline $\mathrm{HRV}_{\mathrm{SD} 2}$ & $75.3 \pm 9.5$ & $22.6 \pm 15.2$ & $77.6 \pm 10.6$ & $22.4 \pm 17.0$ & $72.6 \pm 9.0$ & $22.9 \pm 13.7$ \\
\hline $\mathrm{HRVt}_{\text {SDNN }}$ & $73.2 \pm 10.2$ & $21.2 \pm 16.6$ & $76.6 \pm 10.6$ & $24.2 \pm 18.4$ & $69.2 \pm 8.4$ & $17.7 \pm 14.2$ \\
\hline
\end{tabular}

Data are reported as mean and standard deviation ( \pm ); Abbreviations: $\mathrm{HRV}=$ heart rate variability, MLSS = maximal lactate steady state, $S \mathrm{SD}=$ standard deviation, SDNN = standard deviation of all normal RR intervals..

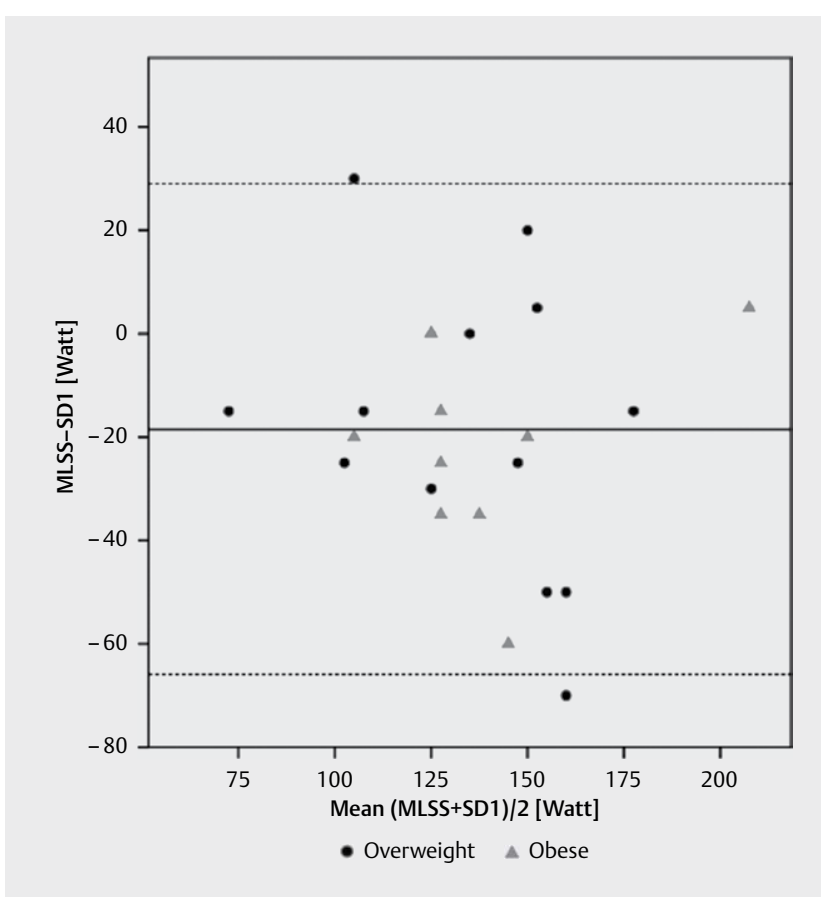

- Fig. 1 Bland-Altman plots for comparing MLSS with $\mathrm{HRV}_{\mathrm{SD} 1}$ for all participants. Dashed line represents limits of agreement corresponding to $\pm 1.96 \mathrm{SD}$. Solid line corresponds to mean of differences.

significant differences between groups ( $\bullet$ Table 4). There were no statistically significant differences between groups for the differences of power output between the MLSS and HRVt ( $\triangleright$ Table 4). For $\mathrm{OW}$ as well as $\mathrm{OB}$ participants, Bland-Altman plots demonstrate moderate to good agreements for all tests with the MLSS ( $\vee$ Fig. $\mathbf{1})$. The lowest discrepancy was observed in $\mathrm{HRVt}_{\text {SDNN }}$ with $16.0 \mathrm{~W}$, whereas the largest discrepancy demonstrated $\mathrm{HRVt}_{\mathrm{SD} 2}$ with $19.8 \mathrm{~W}$. The smallest limit of agreement demonstrated $\mathrm{HRVt}_{\mathrm{SD} 1}$ $(29.0$ to $-65.9 \mathrm{~W})$. The largest limit of agreement reveals $\mathrm{HRVt}_{\text {SDNN }}$ (39.5 to - 71.5). Overall, Bland-Altman plots demonstrated that power at HRVt did not depend on the amount of power output at the MLSS ( Fig. 1-3).

\section{Discussion}

The present study was designed to assess if the MLSS could be detected by HRV in overweight and obese individuals. The results yielded a moderate to strong agreement between the MLSS and HRVt in obese and overweight persons. However, mean differences between the power at the MLSS and the power at all HRVt were relatively large $(-16.0$ to -19.8 W) ( $\bullet$ Fig. $1-3)$. Moreover, all HRVt overestimated the MLSS by a substantial amount ( $\vee$ Table 3 and 4). In accordance with other studies, HRVt were detected at intensities over $60 \% \mathrm{P}_{\max }[1,11,13]$. This seems plausible because the vagal tone is reduced within this zone and several studies demonstrated a relation between vagal withdrawal and $\mathrm{HRVt}$ $[9,11,30,37]$. Only a few studies investigated HRVt in obese or overweight individuals, and these focused solely on comparisons with ventilatory thresholds (VTs). Shibata et al. [44] demonstrated a significant positive correlation ( $r=0.74)$ between $\mathrm{HR}$ at HRVt and VT in obese women. Vasconcellos et al. [38]investigated adolescent boys and reported high correlations between HRVt and VT $(r=0.8-r=0.9)$. Bland-Altman plots demonstrated only small discrepancies in oxygen consumption between HRVt and VT $\left(\mathrm{VO}_{2}\right.$ : $\left.3.94 \mathrm{ml} \cdot \mathrm{kg}^{-1} \cdot \mathrm{min}^{-1}\right)$, and the mean difference of power output between HRVt and VT was only 2.8 W [38]. In contrast to our results, in both studies HRVt underestimated VT [30,38]. Quinart et al. [27] investigated twenty adolescents and measured HRVt as well as 2 different VTs (VT1, VT2) during incremental exercise test 


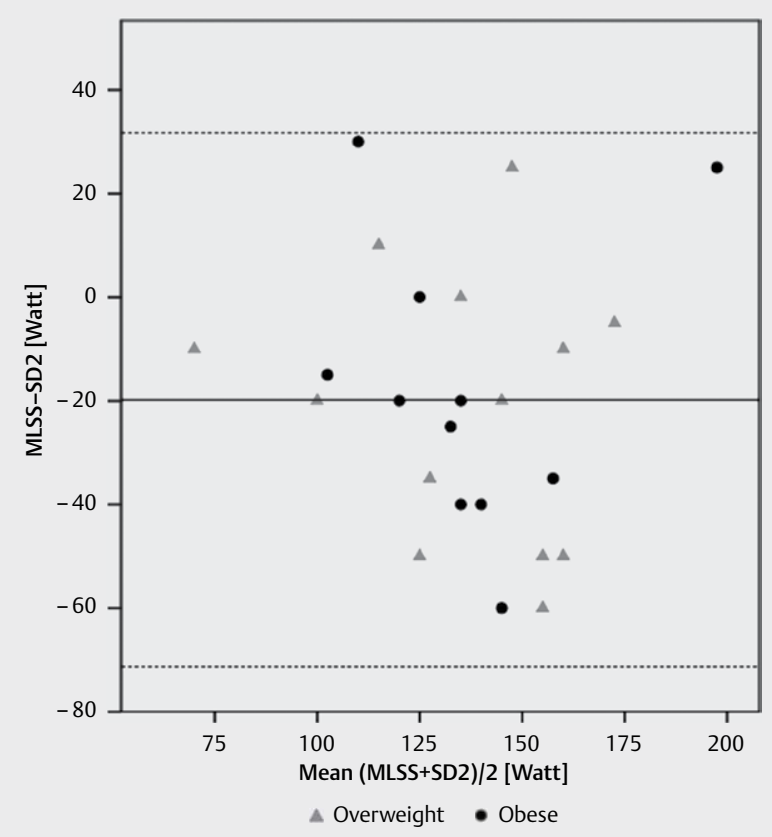

- Fig. 2 Bland-Altman plots for comparing MLSS with $\mathrm{HRV}_{\mathrm{SD} 2}$ for all participants. Dashed line represents limits of agreement corresponding to $\pm 1.96 \mathrm{SD}$. Solid line corresponds to mean of differences.

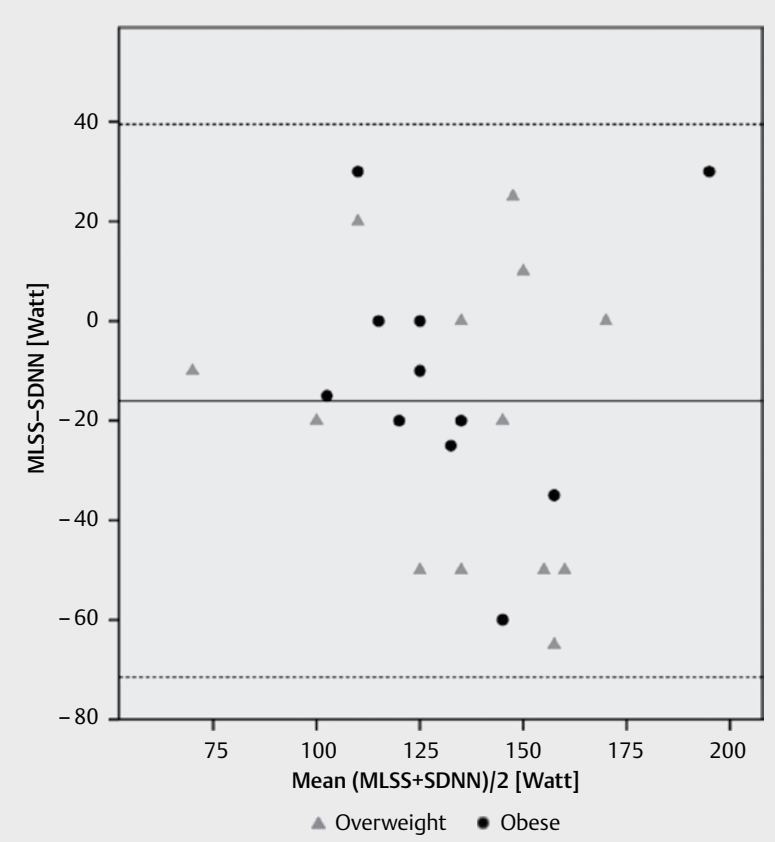

-Fig. 3 Bland-Altman plots for comparing MLSS with HRV SDNN $_{\text {for }}$ all participants. Dashed line represents limits of agreement corresponding to $\pm 1.96 \mathrm{SD}$. Solid line corresponds to mean of differences.

on a cycle ergometer. The authors demonstrated a high correlation $(r=0.93)$ between the VT2 and HRVt and a small difference in power output at HRVt and VT2 (3.2 W). In line with our findings, HRVt overestimated VT2. The VT2 is characterized by respiratory compensation of load-induced metabolic acidosis and corresponds with exceeding the MLSS [7]. This fact could explain the agreement between both investigations. Overall, the above-mentioned studies demonstrated higher correlations compared to our investigation. However, comparisons between the MLSS and VT seem problematic because both concepts reflect similar but different pathophysiological conditions.

Various studies investigated the relationship between different LT and HRVt in normal-weight subjects [18, 21]. However, only one study group compared HRVt with the MLSS. Flöter et al. [13] demonstrated only slight discrepancies $(0.4-5.2 \mathrm{~W})$ and high correlations $(r=0.80-r=0.89)$ between the power at the MLSS and the power at HRVt on a cycle ergometer in healthy trained adults. These results are in contrast to the findings we presented here for overweight and obese subjects. The $\mathrm{OB}$ and $\mathrm{OW}$ demonstrated relatively large discrepancies $(-16.0$ to $-19.8 \mathrm{~W}$ ) ( $\triangleright$ Fig. $1-4)$ and only moderate correlations $(r=0.56-r=0.76)$ ( $($ Table 3$)$. Both investigations were conducted by the same study group and the test protocols were nearly identical. Hence, an influence of body fat during incremental exercise can be considered. Various studies demonstrated a greater vagal withdrawal and increased sympathetic activation compared to normal-weight individuals during rest conditions $[22,28,40]$. It can be assumed that this disturbance of the autonomic nervous system (ANS) is also present during exercise. This disturbance could explain the relatively large discrepancies of the $\mathrm{OB}$ and $\mathrm{OW}$ participants. Interestingly, all HRVt were detected at higher intensities $\left(69.2-77.6 \% \mathrm{P}_{\max }\right)$ compared to the MLSS $\left(62.6-66.8 \% \mathrm{P}_{\max }\right)(\triangleright$ Table 4$)$. As a consequence, all HRVt overestimated the MLSS by a substantial amount ( -16.8 to $-22.9 \mathrm{~W})$ ( $\vee$ Table 4). This was unexpected because various studies demonstrated a maximal vagal withdrawal and an increase of the sympathetic activation close to the LT $[18,21]$. Therefore, our results suggest a delayed vagal withdrawal and a delayed increase of the sympathetic activation during incremental exercise in obese and overweight persons.

Because HRV represents different parts of the ANS, we analyzed various HRV parameters. The primarily vagal-modulated parameter $\mathrm{HRVt}_{\text {SD1 }}[15,35]$ revealed for all subjects and $\mathrm{OB}$ higher correlations $(r=0.69-r=0.76)$ and lower differences $(16.8-22.4 \%)$ compared to the parameter $\mathrm{HRVt}_{\mathrm{SD} 2}(\mathrm{r}=0.56-\mathrm{r}=0.66 ; 22.6-22.9 \%)$ ( $\triangleright$ Table 3 ), which is vagally as well as sympathetically influenced [37]. This is in contrast to Flöter et al. [13], who did not observe relevant differences between the vagally as well as sympathetically influenced parameters. The reason for this may be the considerable lower discrepancies $(0.4-5.2 \mathrm{~W})$ and higher correlations $(r=0.80-r=0.89)$ reported by Flöter et al. [13]. The time-domain parameter $\mathrm{HRV}_{\text {SDNN }}$ reflects the overall variability [34] and demonstrated only weak correlations $(r=0.55-r=0.59)$. However, $\mathrm{HRV}_{\text {SDNN }}$ demonstrated the lowest discrepancy to the MLSS $(-16.0 \mathrm{~W})$ compared to $\mathrm{HRVt}_{\mathrm{SD} 1}(-18.5 \mathrm{~W})$ and $\mathrm{HRVt}_{\mathrm{SD} 2}(-19.8 \mathrm{~W})$. To our knowledge, only one study investigated the parameter SDNN in relation to LT. In contrast to this investigation, Karapetian et al. [18] demonstrated a high correlation $(r=0.82)$ for $\mathrm{VO}_{2}$ between $\mathrm{HRVt}$ based on SDNN and LT in healthy adults with a wide range of aerobic capacities. Only a few studies investigated time-domain parameters in obese or overweight individuals. Quinart et al. [27] reported a strong correlation $(r=0.78)$ and a low mean difference $(5.8 \mathrm{~W})$ be- 
tween the time-domain parameter of the root mean square of successive differences (rMSSD) and VT in obese adolescents. Vasconcellos et al. [38] also demonstrated high correlations between the parameter rMSSD and VT $(r=0.8-r=0.9)$ and a low mean difference of power $(2.8 \mathrm{~W})$ in adolescent boys. The parameter rMSSD represents primarily the vagal activity [20], which is strongly associated with ventilation $[8,10,14,15,50]$. This could explain the high correlations between HRVt based on rMSSD and VT in the studies of Vasconcellos et al. [38] and Quinart et al. [27]. Therefore, time-domain analyses seem to be useful to detect LT in healthy adults [18] and to detect VT in obese persons $[27,38]$. However, the results of this study indicated that the overall variability parameter SDNN is inadequate to identify the MLSS in obese or overweight individuals.

A comparison of group outcomes demonstrated only slight differences between OB and OW ( $\downarrow$ Table 3 and $\$ 4$ ). OB revealed a higher correlation and a lower difference for $\mathrm{HRV}_{\mathrm{SD} 1}(r=0.76$, $16.8 \%$ ) compared to the OW ( $r=0.66,22.4 \%)$. In contrast, OW exhibited a higher correlation and a lower difference for $\mathrm{HRV}_{\mathrm{SD} 2}$ $(r=0.66,22.4 \%)$ compared to the OB $(r=0.56,22.6 \%)$. Furthermore, OB reached HRVt at lower values of \% $\mathrm{P}_{\max }(69.2-72.9 \%)$ in comparison to the OW (72.5-75.6\%) ( Table 4). This could be explained by the fact that an increase of body fat is associated with a decrease of HRV [33]. It should be noted that the OB revealed high values for the vagally modulated parameter $\mathrm{HRVt}_{\mathrm{SD} 1}(r=0.76)$ but a considerable lower correlation for the vagally as well as sympathetically influenced parameter $\mathrm{HRVt}_{\mathrm{SD} 2}(r=0.56)$ ( $>$ Table 3). This is in contrast to Flöter et al. [13], who did not observe relevant differences between vagal-modulated and vagally as well as sympathetically influenced parameters. This indicated a higher sensitivity of the primarily vagally modulated parameters in detecting the MLSS in obese and overweight persons. $\mathrm{HRVt}_{\text {SDNN }}$ demonstrated only weak correlations for both groups ( $r=0.56$ to $r=0.59$ ). Therefore, the overall variability parameter SDNN is inadequate to identify the MLSS in obese or overweight individuals.

\section{Limits}

Some limitations of this study need to be considered. The detection of HRVt did not succeed for all participants. For 2 participants, HRVt could not be determined because of the insufficient quality of the ECG. The reason for this remains unclear. Possibly it might have been caused by body fat or the irregular ECG signal induced by exercise. Other studies that investigated obese participants did not report any data in this context $[27,30,38]$. Furthermore, the relatively small sample size is a limiting factor. $\mathrm{HRVt}_{\mathrm{SD} 2}$ and $\mathrm{HRVt}_{\mathrm{S}}$ DNN were determined by visual evaluation. This constitutes a methodological bias but represents the commonly used method in practice. Moreover, HRV analyses were conducted by specifically developed software. This is in contrast to recommendations for HRV analysis [34] and to other studies but did make it possible to observe and process the raw data.

\section{Conclusion}

The results of this study extended previous findings about HRV and LT. Moderate to strong agreements between HRVt and the MLSS in overweight and obese persons were demonstrated. Specifically, the foremost vagally modulated parameter $\mathrm{HRVt}_{\mathrm{SD} 1}$ revealed a higher correlation and lower differences compared to the vagally and sympathetically influenced parameters $\mathrm{HRVt}_{\mathrm{SD} 2}$. This indicates a higher sensitivity of the foremost vagal modulated parameters to detect the MLSS in obese and overweight subjects. Moreover, HRVt were detected at higher intensities compared to the MLSS, which suggests a delayed vagal withdrawal during incremental exercise in obese and overweight persons.. In comparison with other studies, HRVt overestimated MLSS by a substantial amount. In the light of these findings, the use of HRV to determine the MLSS in obese and overweight subjects seems questionable.

\section{Acknowledgements}

We thank all the subjects for participating in the study. We thank cardioscan $\mathrm{GmbH}$ (Hamburg) for equipment support.

\section{Conflict of Interest}

Authors declare that they have no conflict of interest.

\section{References}

[1] Anosov O, Patzak A, Kononovich Y, Persson PB. High-frequency oscillations of the heart rate during ramp load reflect the human anaerobic threshold. Eur J Appl Physiol 2000; 83: 388-394

[2] Aubert AE, Seps B, Beckers F. Heart rate variability in athletes. Sport Med 2003; 33: 889-919

[3] Balady G], Arena R, Sietsema K, Myers ], Coke L, Fletcher GF, Forman D, Franklin B, Guazzi M, Gulati M, Keteyian SJ, Lavie CJ, MacKo R, Mancini D, Milani RV. Clinician's guide to cardiopulmonary exercise testing in adults: A scientific statement from the American heart association. Circulation 2010; 122: 191-225

[4] Baynard T, Goulopoulou S, Sosnoff R, Fernhall B, Kanaley J. Cardiovagal modulation and efficacy of aerobic exercise training in obese individuals. Med Sci Sports Exerc 2014; 46: 369-375

[5] Bellenger CR, Fuller JT, Thomson RL, Davison K, Robertson EY, Buckley JD. Monitoring athletic training status through autonomic heart rate regulation: A systematic review and meta-analysis. Sport Med 2016; 46: $1461-1486$

[6] Beneke R. Methodological aspects of maximal lactate steady stateimplications for performance testing. Eur J Appl Physiol 2003; 89: 95-99

[7] Binder RK, Wonisch M, Corra U, Cohen-Solal A, Vanhees L, Saner H, Schmid J-P. Methodological approach to the first and second lactate threshold in incremental cardiopulmonary exercise testing. Eur J Cardiovasc Prev Rehabil 2008; 15: 726-734

[8] Blain G, Meste O, Bermon S. Influences of breathing patterns on respiratory sinus arrhythmia in humans during exercise. Am J Physiol Hear Circ Physiol 2005; 288: 887-895

[9] Blain G, Meste O, Bouchard T, Bermon S. Assessment of ventilatory thresholds during graded and maximal exercise test using time varying analysis of respiratory sinus arrhythmia. Br J Sports Med 2005; 39: 448-452

[10] Bland JM, Altman DG. Statistical methods for assessing agreement between two methods of clinical measurement. Lancet 1986; 327 : 307-310 
[11] Cottin F, Leprêtre PM, Lopes P, Papelier Y, Médigue C, Billat V. Assessment of ventilatory thresholds from heart rate variability in well-trained subjects during cycling. Int J Sports Med 2006; 27: 959-967

[12] Faude O, Kindermann W, Meyer T. Lactate threshold concepts. How valid are they? Sport Med 2009; 39: 469-490

[13] Flöter N, Schmidt T, Keck A, Reer R, Jelkmann W, Braumann K. Assessment of the individual anaerobic threshold from heart rate variability in interdependency to the activity of the sympathetic activation. Dtsch Z Sportmed 2012; 63: 41-45

[14] Garber CE, Blissmer B, Deschenes MR, Franklin BA, Lamonte MJ, Lee IM, Nieman DC, Swain DP. American College of Sports Medicine position stand. Quantity and quality of exercise for developing and maintaining cardiorespiratory, musculoskeletal, and neuromotor fitness in apparently healthy adults: Guidance for prescribing exercise. Med Sci Sports Exerc 2011; 43: 1334-1359

[15] Guzik P, Piskorski ], Krauze T, Schneider R, Wesseling KH, Wykretowicz A, Wysocki H. Correlations between the Poincaré plot and conventional heart rate variability parameters assessed during paced breathing. J Physiol Sci 2007; 57: 63-71

[16] Harriss DJ, Macsween A, Atkinson G. Standards for ethics in sport and exercise science research: 2018 update. Int J Sports Med 2017; 38: 1126-1131

[17] Heck H, Mader A, Hess G, Mücke S, Müller R, Hollmann W. Justification of the 4-mmol/I lactate threshold. Int J Sports Med 1985; 6: 117-130

[18] Karapetian GK, Engels HJ, Gretebeck RJ. Use of heart rate variability to estimate LT and VT. Int J Sports Med 2008; 29: 652-657

[19] Keating SE, Johnson NA, Mielke GI, Coombes JS. A systematic review and meta-analysis of interval training versus moderate-intensity continuous training on body adiposity. Obes Rev 2017; 18: 943-964

[20] McLachlan CS, Ocsan R, Spence I, Hambly B, Matthews S, Wang L, Jelinek HF. Increased total heart rate variability and enhanced cardiac vagal autonomic activity in healthy humans with sinus bradycardia. Proc (Bayl Univ Med Cent) 2010; 23: 368-370

[21] Di Michele R, Gatta G, Di Leo A, Cortesi M, Andina F, Tam E, Da Boit M, Merni F. Estimation of the anaerobic threshold from heart rate variability in an incremental swimming test. J Strength Cond Res 2012; 26: 3059-3066

[22] Muralikrishanan K, Balasubramanian K, Ali S, Rao B. Poincare plot of heart rate variability: An approach towards explaining the cardiovascular autonomic function in obesity. Indian J Physiol Pharmacol 2013; 57: 31-37

[23] Ng M, Fleming T, Robinson M, Thomson B, Graetz N, Margono C, Mullany E, Gakidou E. Global, regional and national prevalence of overweight and obesity in children and adults 1980-2013: A systematic analysis. Lancet 2014; 384: 766-781

[24] Parizkova J, Buzkova P. Relationship between skinfold thickness measured by Harpenden caliper and densitometric analysis of total body fat in men. Hum Biol 1971; 43: 16-21

[25] Petretta M, Bonaduce D, de Filippo E, Mureddu G, Scalfi L, Marciano F, Bianchi V, Salemme L, de Simone G, Contaldo F. Assessment of cardiac autonomic control by heart period variability in patients with early-onset familial obesity. Eur J Clin Invest 1995; 25: 826-832
[26] Plews D], Laursen PB, Stanley J, Kilding AE, Buchheit M. Training adaptation and heart rate variability in elite endurance athletes: Opening the door to effective monitoring. Sport Med 2013; 43: 773-781

[27] Quinart S, Mourot L, Négre V, Simon-Rigaud M, Nicolet-Guénat M, Bertrand A, Meneveau N, Nougin F. Ventilatory thresholds determined from HRV: Comparison of 2 methods in obese adolescents. Int J Sports Med 2013; 35: 202-208

[28] Rabbia F, Silke B, Conterno A, Grosso T, De Vito B, Rabbone I, Chiandussi L, Veglio F. Assessment of cardiac autonomic modulation during adolescent obesity. Obes Res 2003; 11: 541-548

[29] Ramos JS, Dalleck LC, Tjonna AE, Beetham KS, Coombes JS. The impact of high-intensity interval training versus moderate-intensity continuous training on vascular function: A systematic review and meta-analysis. Sport Med 2015; 45: 679-692

[30] Shibata M, Moritani T, Miyawaki T, Hayashi T, Nakao K. Exercise prescription based upon cardiac vagal activity for middle-aged obese women. Int J Obes 2002; 26: 1356-1362

[31] Stegmann H, Kindermann W, Schnabel A. Lactate kinetics and individual anaerobic threshold. Int J Sport Med 1981; 3: 160-165

[32] Svedahl K, Maclntosh B. Anaerobic threshold: the concept and methods of measurment. Can J Appl Physiol 2003; 28: 299-323

[33] Sztajzel J, Golay A, Makoundou V, Lehmann TNO, Barthassat V, Sievert K, Pataky Z, Assimacopoulos-Jeannet F, Bobbioni-Harsch E. Impact of body fat mass extent on cardiac autonomic alterations in women. Eur J Clin Invest 2009; 39: 649-656

[34] Task Force of the European Society of Cardiology the North American Society of Pacing Electrophysiology. Heart rate variability standards of measurement, physiological interpretation, and clinical use. Circulation 1996; 93: 1043-1065

[35] Tsuji H, Larson M, Venditti F, Manders E, Evans JCF, Levy D. Impact of reduced heart rate variability on risk for cardiac events. Circulation 1996; 94: 2850-2855

[36] Tulppo M, Mäkikallio T, Seppänen T, Airaksinen J, Huikuri H. Heart rate dynamics during accentuated sympathovagal interaction. Am J Physiol Hear Circ Physiol 1998; 274: H810-H816

[37] Tulppo M, Mäkikallio T, Takala T, Seppänen T, Huikuri H. Quantitative beat-to-beat analysis of heart rate dynamics during exercise. Am J Physiol Hear Circ Physiol 1996; 271: H244-H252

[38] Vasconcellos F, Seabra A, Montenegro R, Cunha F, Bouskela E, Farinatti P. Can heart rate variability be used to estimate gas exchange threshold in obese adolescents? Int J Sports Med 2015; 36: 654-660

[39] Wewege M, van den Berg R, Ward RE, Keech A. The effects of high-intensity interval training vs. moderate-intensity continuous training on body composition in overweight and obese adults: A systematic review and meta-analysis. Obes Rev 2017; 18: 635-646

[40] Zahorska-Markiewicz B, Kuagowska E, Kucio C, Klin M. Heart rate variability in obesity. Int J Obes Relat Metab Disord 1993; 17: 21-23 